\title{
Enabling and coercive management control systems and organizational resilience ${ }^{\star}$
}

\author{
Ilse Maria Beuren ${ }^{1}$ \\ (D) https://orcid.org/0000-0003-4007-6408 \\ Email: ilse.beuren@ufsc.br \\ Vanderlei dos Santos ${ }^{2}$ \\ (D) https://orcid.org/0000-0002-9841-3780 \\ Email: vanderlei.santos@udesc.br
}

\begin{abstract}
1 Universidade Federal de Santa Catarina, Centro Socioeconômico, Programa de Pós-Graduação em Contabilidade, Florianópolis, SC, Brazil ${ }^{2}$ Universidade do Estado de Santa Catarina, Centro de Educação Superior do Alto Vale do Itajaí, Departamento de Ciências Contábeis, Ibirama, SC, Brazil
\end{abstract}

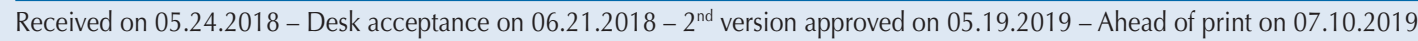

Associate Editor: Claudio Wanderley

\begin{abstract}
This study examines the impacts of enabling and coercive management control systems (MCSs) on organizational resilience, in the cognitive, behavioral, and contextual dimensions. Research on resilience has sought to identify elements capable of improving organizational resilience capacity, and enabling and coercive MCSs may shed new light on this discussion. Understanding the role of MCSs in the creation and use of resilience capacities can help explain why some organizations manage to outperform others in situations of adverse and turbulent events. The literature has focused on enabling MCSs and adopts the premise that, in general, the use of coercive controls is negatively perceived. However, the results of the research show that enabling and coercive MCSs coexist in companies, and that coercive controls do not have a negative influence on resilience, even showing a positive association with the contextual dimension. A survey was conducted in companies that bought and/or were acquired by others, according to PwC Brazil's Mergers and Acquisitions report, and the sample consists of 144 managers from different organizational areas of these companies who answered the questionnaire sent via Survey Monkey. The structural equation modeling (SEM) technique was applied to test the hypotheses. The study presents evidence that MCSs constitute antecedents of resilience capacity in organizations. This suggests that the design and use of MCSs may favor the development of capacities to deal with turbulences and unexpected events in advance.
\end{abstract}

Keywords: management control systems, enabling control, coercive control, organizational resilience.

Correspondence address

Ilse Maria Beuren

Universidade Federal de Santa Catarina, Centro Socioeconômico

Campus Universitário Reitor João David Ferreira Lima - CEP 88040-900

Trindade - Florianópolis - SC - Brazil

*Article presented at the XLI ANPAD Conference, October of 2017, São Paulo, SP, Brazil. 


\section{INTRODUCTION}

Although the scope of the term resilience may change among the various fields of knowledge, its concept relates with the capacity of an element to return to a stable state after an interruption (Bhamra, Dani \& Burnard, 2011). In the organizational context, the concept does not change dramatically (Bhamra et al., 2011); it refers to the capacity to handle turbulences and unexpected events in advance (Annarelli \& Nonino, 2016). For Lengnick-Hall and Beck (2005), resilience is the capacity to interpret unknown situations in order to devise new ways to deal with such events, as well as mobilizing people, resources, and processes in order to transform these choices.

Resilience is considered to be an essential organizational capacity for organizations that operate in turbulent environments (Lengnick-Hall, Beck \& Lengnick-Hall, 2011). It is generally seen as a desirable characteristic, which allows an organization and its members to deal with different adversities (Linnenluecke, 2017). The literature suggests that resilient companies present superior performance compared to non-resilient ones (Akgün \& Keskin, 2014), since organizational resilience enables environmental conditions to be more precisely assessed and the most effective strategy to be chosen in the event of turbulent environments that are in constant evolution (Lengnick-Hall et al., 2011).

However, systematic reviews of the literature, such as those by Bhamra et al. (2011), Linnenluecke (2017), and Ruiz-Martin, López-Paredes, and Wainer (2018), indicate that there are a limited number of empirical studies regarding explanatory factors or attributes that can contribute to improving organizational resilience levels. Barasa, Mbau, and Gilson (2018) note that the literature relating to resilience is predominantly conceptual. Luthans, Vogelgesang, and Lester (2006) and LengnickHall et al. (2011) focused their studies on human resources policies for developing resilience and recommend that organizations develop competences in key employees to support the organization's resilience capacity.

Ignatiadis and Nandhakumar (2007), Chewning, Lai, and Doerfel (2012), and Alvarenga, Santos, and Pelissari (2017) investigated resilience in the context of information systems. These studies provide evidence that the design and use of the system influence individual and organizational resilience. Yet, one limitation of this line of research is that only one instance of information systems in the whole company was examined, that of Enterprise Resource Planning (Ignatiadis \& Nandhakumar, 2007). In this study, it is conjectured that a management control system (MCS), from a broader perspective, can both inhibit and enable resilience in organizations.

MCSs were also the focus of the research by Bisbe and Otley (2004), who found evidence that they provide precise information and, in a short space of time, contribute to improving the way organizations deal with uncertainties. Inspired by principles from the area of systems, technology, and automation, Adler and Borys (1996) propose that, in accordance with the theory of bureaucratic formalization, formal systems may have enabling characteristics, by granting greater responsibility and autonomy to employees, or coercive characteristics, by designing rigid and barely-interactive processes. These characteristics, when attributed to MCSs, denote that enabling controls can favor greater employee integration with their activities in the company, while coercive controls present the opposite tendency (Ahrens \& Chapman, 2004).

In this context, there is the presumption of a possible association between both enabling and coercive MCSs and organizational resilience. Thus, the study seeks to answer the following research question: what are the impacts of enabling and coercive MCSs on organizational resilience in companies that have bought and/or been acquired by others? Hence, the study aims to examine the impacts of enabling and coercive MCSs on organizational resilience. Based on the study by Adler and Borys (1996), an MCS is conceived as a mechanism with enabling and coercive characteristics that has an influence on organizational resilience in the event of changes occurring in the organizational context.

The study contributes to the field of knowledge by examining the relationship between both enabling and coercive MCSs and organizational resilience. Change is an inevitable characteristic in organizations, whether due to external effects, some natural consequence, or some strategic initiative to increase competitive advantage (Lengnick-Hall et al., 2011). Thus, organizations must be able to alter their resources, competences, and business models in order to resolve problems, leverage resources and capacities, and explore and exploit new opportunities. Understanding the role of MCSs in the creation and use of resilience capacities offers a new way of explaining why some companies manage to outperform others during adverse and turbulent events. The research also provides a practical contribution, since it supports the understanding of how MCSs should be planned and used for organizations to deal with 
changes and unexpected events. The study broadens the discussion of the research on information systems and organizational resilience (Chewning et al., 2012) by addressing aspects of MCSs.

Finally, the taxonomy of enabling and coercive controls proposed by Adler and Borys (1996) still presents some research gaps. The systematization of the studies regarding this taxonomy has mostly (Chapman \& Kihn, 2009; Mahama \& Cheng, 2013; Souza \& Beuren, 2018) only covered enabling characteristics. Burney, Radtke, and Widener (2017) argue that the literature has focused on the enabling use of MCSs because it is thought that this is more beneficial than the coercive use. However, theoretical-empirical evidence (Ahrens \& Chapman 2004; Hartmann \& Maas, 2011; Mundy, 2010; Tessier \& Otley, 2012) suggests that MCSs play two complementary and interdependent roles: their use to exercise control in the achievement of organizational objectives and for employees to seek opportunities and resolve problems. In this research, the premise is that MCSs can play a coercive and/or enabling role and that this is reflected in organizational resilience.

\section{LITERATURE REVIEW}

\subsection{Organizational Resilience}

The term resilience emerged in the physical sciences and refers to a system's capacity to recover its previous form after a disturbance (Annarelli \& Nonino, 2016). The common use of the word resilience implies the capacity of an element, system, individual, or organization to return to its normal condition after the occurrence of an event that disturbs its state (Hosseini, Barker \& Ramirez-Marquez, 2016). The authors mention that there are various concepts of resilience circulating in the literature, although there is an overlap with a set of already-existing concepts, such as fault tolerance, flexibility, survival capacity, and agility.

Bhamra et al. (2011) explain that the concept of resilience is multidisciplinary and multifaceted. The idea of resilience is firmly based on ecology and the definitions used in various studies have followed the propositions of Holling (1973), whose research was related to the stability of the ecosystem. Thus, there have been various definitions proposed for resilience, each one slightly different, depending on the context (Bhamra et al., 2011). In the organizational field, resilience is analyzed based on different perspectives, for example using an individual, sectorial, organizational, social, as well as a supply chain focus (Lengnick-Hall et al., 2011).

The concept of organizational resilience emerged for companies to respond to a rapidly-changing business environment (Hosseini et al., 2016). From this perspective, the seminal studies conducted by Staw, Sandelands, and Dutton (1981) and Meyer (1982) stand out, which focused primarily on the responses of organizations to external threats. Based on a literature review, Ruiz-Martin et al. (2018) observed that there are three main lines in the conceptualization of organizational resilience: (i) resilience as a characteristic of an organization (something that an organization has); (ii) resilience as the result of an organization's activities (something that an organization does); and (iii) resilience as a measure of the disruptions that an organization can tolerate. All these lines present a common meaning and emphasize the organization's survival by dealing with shocks, risks, and changes.

Somers (2009) and Lengnick-Hall et al. (2011) mention that the literature offers two different perspectives for organizational resilience: passive and active. From the passive stance, resilience is associated with an organization's capacity and ability to return to a stable state after an interruption, such as resolving problems relating to current products (Akgün \& Keskin, 2014; Bhamra et al. 2011; Gittell, Cameron, Lim \& Rivas, 2006). From this perspective, resilience in portrayed as an organization's capacity to recover from unexpected, stressful, and adverse situations and return to its previous situation (Gittell et al. 2006).

Resilience conceived based on an active approach implies an organization being proactive in order to ensure that it prospers in the event of adversity and turbulence (Lengnick-Hall et al., 2011), with new and better products, instead to reacting to problems related to current products (Akgün \& Keskin, 2014), as well as developing capacities to create new opportunities before disruptive events occur (Somers, 2009). Thus, resilience is linked to the company's capacity to absorb complexities and emerge from a challenging situation stronger and with a greater repertoire of actions before the disruptive event arises (Lengnick-Hall et al., 2011).

Lengnick-Hall and Beck (2005) and Lengnick-Hall et al. (2011) adopted the active aspect of organizational resilience as resilience capacity. These authors suggest that resilience capacity is developed based on a combination of cognitive, behavioral, and contextual capacities at an organizational level. They propose that as an organization develops its resilience capacity, it will come to interpret 
uncertain situations more creatively (cognitive resilience) and will, therefore, be more capable of devising unfamiliar and unconventional activities (behavioral resilience) and taking advantage of relationships and resources (contextual relationship). Resilience capacity provides the basis for a company to respond to uncertainty (LengnickHall \& Beck, 2005).

Ruiz-Martin et al. (2018) explain that each dimension provides the organization with some resources. Cognitive resilience enables the organization to perceive, interpret, analyze, and formulate responses that go beyond its survival. Behavioral resilience makes the organization work. The elements that contribute to building behavioral resilience are an inventory of complex and varied actions and functional habits or routines. Contextual resilience is a structure in which cognitive and behavioral resilience occurs. The characteristics used to create contextual resilience are social capital and an extensive resource network (Ruiz-Martin et al., 2018).

Lengnick-Hall and Beck (2005) and Lengnick-Hall et al. (2011) remained in the theoretical field, without operationalizing and validating their construct, and focused specifically on organizational resilience capacity from the people management perspective. Akgün and Keskin (2014) operationalized and empirically tested organizational resilience capacity (cognitive, behavioral, and contextual) and analyzed its impact on product innovation and organizational performance. In this research, resilience is analyzed in a wider organizational context and as one of the consequences of the MCS.

\subsection{Enabling and Coercive MCSs}

MCS is a broad concept, but in essence it represents a strategic and operational control system that integrates the functions of organizational, personnel, and cultural control (Chenhall, 2003). It includes instruments and systems that managers use to ensure that the behaviors and decisions of employees are consistent with organizational objectives and strategies (Malmi \& Brown, 2008). This concept covers the design and use of the elements that compose it. In this research, the MCS is analyzed based on the framework of Adler and Borys (1996), who propose a reconciliation between the positive and negative aspects of bureaucracy based on two types of formalization: enabling and coercive.

Enabling formalization proposes rules and systems planned to facilitate the structure and refine and steer its work processes, without necessary hierarchical implications (Adler \& Borys 1996). Therefore, they are rules and systems meant to support, instead of controlling the employee. In contrast, coercive formalization covers rules and systems planned to force compliance with pre-specified standards (Adler \& Borys, 1996; Ahrens \& Chapman, 2004). Coercive formalization aims to force employee conformity, while enabling formalization makes employees feel facilitated and motivated by the rules and systems in place (Wouters \& Wilderom, 2008).

The distinction between enabling and coercive formalization depends on the characteristics of the formalization and the system's design and implementation process (Adler \& Borys, 1996). The formalization characteristics that underpin the design of enabling and coercive controls are: repair, internal transparency, global transparency, and flexibility (Ahrens \& Chapman, 2004; Hartmann \& Maas, 2011). Ahrens and Chapman (2004) report that repair includes a design for dividing the control processes and provides resources to correct them. This requires internal transparency (an understanding of the workings of the local processes) and global transparency (an understanding of where and how these local processes fit into the organization). It also implies flexibility, which refers to the criterion of the organization's members regarding the use of control systems, which can even include switching them off.

Adler and Borys (1996) developed a theoretical study concerning the characteristics of formalization and the system's design and implementation process, while Ahrens and Chapman (2004) empirically demonstrated that the characteristics of formalization that underpin the design and use of enabling and coercive controls are relevant for the study of MCSs. Ahrens and Chapman (2004) highlight that MCSs are more strongly linked to questions of hierarchy and performance evaluation than to machine production technology, and that the framework proposed by Adler and Borys (1996) offers a general approach for understanding the way in which accounting practices can combine mechanistic and organic characteristics. Although Ahrens and Chapman (2004) proposed these four principles on which to base the design of enabling controls, Adler and Borys (1996) also provided a basis for designing coercive controls.

Control mechanisms can be categorized on a enabling versus coercive continuum (Sánchez, Vélez \& RamónJerónimo, 2012). For example, Hartmann and Maas (2011) suggest that the budgetary process is coercive when it clearly limits freedom of managerial action, used to communicate to the people in an organization how they must behave and to communicate to managers what they are allowed and not allowed to do. In turn, an enabling budgetary process provides a structure for discussing managers' decisions and actions and stimulates 
interaction at different hierarchical levels. Another example is the enabling performance measurement system (PMS), perceived by workers as a facilitator of their responsibilities, and not as a control device for use by senior management (Wouters \& Wilderom, 2008).

In general, coercive controls are characterized by compliance with rules, punishment of mistakes, and the spreading of distrust, in which the unexpected is feared and problems are seen as obstacles, while enabling controls support an interactive dialogue, take pleasure in the unexpected, and promote trust, and problems are seen as opportunities (Hoy \& Sweetland, 2001). The coercive use concentrates on controlling behavior, while the enabling use focuses on facilitating autonomy and learning (Radtke \& Widener, 2016).

\subsection{Developing the Hypotheses}

Theoretical arguments and some empirical evidence, although from other areas of knowledge, support the insight that enabling and coercive MCSs are associated with organizational resilience due to their characteristics. Resilient organizations need structured processes that provide learning based on a wide range of successful and unsuccessful experiences (Lee, Vargo \& Seville, 2013). Resilience is characterized as being dependent on how information is managed and used (Barasa et al., 2018). It involves a dynamic capacity for organizational adaptation that grows and develops over time (Gittel et al. 2006). It results from the capacity for organizations to flexibility monitor what is occurring, anticipate interruptions, and learn from experience (Lee et al., 2013).

Enabling MCSs are planned to incentivize the sharing of information, worker interaction, learning opportunities, and problem solving. According to Free (2007), enabling controls grant the freedom to innovate amidst contingencies, unexpected events, and obstacles that can hamper the organization's goals, objectives, and productivity. Therefore, they enable organizations to return to their previous state in the event of some adversity or, also, to prosper during turbulences, becoming more resilient.

Flexibility also constitutes a key element of resilience (Annarelli \& Nonino, 2016). Jørgensen and Messner (2009) explain that flexibility is desirable whenever it is not explicitly clear ex ante how a specific objective should be achieved or how a particular activity should be carried out. Sheffi and Rice (2005) warn that the most important step for companies to increase their resilience is to increase their flexibility and capacity for adaptation. This is based on the characteristics of repair, internal transparency, global transparency, and flexibility of the enabling control, proposed by Adler and Borys (1996) and empirically tested by Ahrens and Chapman (2004), Free (2007), Hartmann and Maas (2011), and Mahama and Cheg (2013). In the research by Jørgensen and Messner (2009), it was observed that, in the case of organizational change, the enabling control, in comparison with the coercive one, may be more beneficial, since it allows employees to repair the MCS in light of new needs and circumstances.

Ignatiadis and Nandhakumar (2007) analyzed the relationship between control and organizational resilience based on the implementation of the Enterprise Resource Planning (ERP) system in a company. They observed that this occurs through the incorporation and breaking down of information and the creation of power differentials. They also found that too much control may streamline company operations, but at the same time it can reduce resilience to respond to future changes. Little control can cause excessive deviation and can also be damaging. According to Ignatiadis and Nandhakumar (2007), the best way is to allow the necessary controls to be implemented in a way that does not stifle the company's capacity to respond to future challenges. Chewning et al. (2012) mention that one of the ways in which organizations can promote resilience during a crisis is by adapting routines, including the use of information technology.

Therefore, the MCS can constitute an antecedent of resilience, under the assumption that its enabling and coercive characteristics are reflected in organizational resilience. It is conjectured that these characteristics affect organizational resilience in the cognitive, behavioral, and contextual dimensions. The development of cognitive resilience involves questioning fundamental assumptions, conceptualizing new and appropriate solutions, and minimizing rules and procedures (Lengnick-Hall et al., 2011). Companies with cognitive resilience seek opportunities to develop new abilities, instead to emphasizing standardization and the need for control. Under the enabling logic, managers and employees are encouraged to discuss problems related to rules and standards (Ahrens \& Chapman, 2004), as well as providing managers with the freedom to innovate amidst contingencies, unexpected events, and obstacles that may hamper the achievement of goals (Free, 2007). An enabling system incentivizes experimentation and dialogue (Wouters \& Wilderom, 2008) and improves the capacities, abilities, and intelligence of the users (Henttu-Aho, 2016). In the coercive MCS, procedures are applied more rigidly (Adler \& Borys, 1996), they are designed to be followed (Free, 2007), and workers are informed about what and when to do things in order to minimize deviations (Ahrens 
\& Chapman, 2004). These characteristics are in contrast with the development of cognitive resilience in terms of conceptual orientation and constructive direction. Conceptual orientation, formed based on a strong sense of purpose and fundamental values, enables problem solving and actions, instead of leading to threat rigidity or a dysfunctional escalation of commitment (Lengnick-Hall et al., 2011). Constructive direction focuses on specific interpretations and judgements regarding a situation, instead of programmed explanations (Lengnick-Hall $\&$ Beck, 2005). It involves reciprocal interaction in the search for information, meaning, attribution, and action (Lengnick-Hall et al., 2011).

Behavioral resilience is the mechanism that drives an organization. This dimension enables a company to learn more about a situation and use its own resources and capacities fully through collaborative actions (Lengnick-Hall et al., 2011). Original/improvised agility and behavioral preparation combine to create behavioral resilience (Lengnick-Hall \& Beck, 2005). According to Akgün and Keskin (2014), behavioral preparation implies an organization deliberately unlearning obsolete information or dysfunctional heuristics, while original/ improvised agility involves following a drastically different course of action from the norm. Open communication, incentives for sharing knowledge and for reflexive practices, experimentation (freedom to fail), and broad work descriptions are some of the characteristics present in MCSs designed under the enabling logic and suggested by Lengnick-Hall et al. (2011) to develop resilience with regards to original agility and behavioral preparation (behavioral dimension).

The contextual conditions that support resilience depend on relationships inside and outside the organization to facilitate effective responses to environmental complexities (Lengnick-Hall \& Beck, 2005). In this aspect, contextual resilience involves the incorporation of a wide network of tangible and intangible resources, as well as indicating the perceptions of individuals, if their work environment is conducive to assuming interpersonal risks (psychological security) (Akgün \& Keskin, 2014). Lengnick-Hall et al. (2011) warn that organizational resilience demands interpersonal risks, which requires establishing a climate of psychological security. Thus, the work environment should be conducive to seeking information, admitting mistakes, experimenting, and offering feedback (Lengnick-Hall \& Beck, 2005). According to Chapman and Kihn (2009), enabling MCSs facilitate flexible responses to emerging events; control systems can even be switched off. Although unconstrained flexibility is not beneficial, enabling MCSs offer a structure with various options, ranging from blocking specific actions to automatic reports.

The resources obtained by a company as a result of its network of organizational relationships ensures some measure of continuous slack, they widen the range of viable actions, and they promote a variety of interpretations for alternative applications of these resources (Lengnick-Hall et al., 2001). This, according to the authors, stimulates innovation and challenges the predominant assumptions. Free (2007) explains that control systems devised under the enabling approach support operational creativity and shape innovation efforts, providing agents with a wide range of information to help them to creatively interact with the processes and organizational environment, while the coercive approach implements procedures and efficiency parameters, rigidly specified to be rigorously followed, with consequences for deviant behaviors. This leads to the formulation of the study hypotheses, which are:

$\mathrm{H}_{1}$ : the enabling controls of an MCS are related to organizational resilience in the cognitive, behavioral, and contextual dimensions, in that they present positive associations with conceptual orientation $\left(\mathrm{H}_{1 \mathrm{a}}\right)$, constructive direction $\left(\mathrm{H}_{1 \mathrm{~b}}\right)$, improvised agility $\left(\mathrm{H}_{1 \mathrm{c}}\right)$, behavioral preparation $\left(\mathrm{H}_{1 \mathrm{~d}}\right)$, psychology $\left(\mathrm{H}_{\mathrm{le}}\right)$, and resource network $\left(\mathrm{H}_{1 \mathrm{f}}\right)$.

$\mathrm{H}_{2}$ : the coercive controls of an MCS are related to organizational resilience in the cognitive, behavioral, and contextual dimensions, in that they present positive associations with conceptual orientation $\left(\mathrm{H}_{2 \mathrm{a}}\right)$, constructive direction $\left(\mathrm{H}_{2 \mathrm{~b}}\right)$, improvised agility $\left(\mathrm{H}_{2 \mathrm{c}}\right)$, behavioral preparation $\left(\mathrm{H}_{2 \mathrm{~d}}\right)$, psychology $\left(\mathrm{H}_{2 \mathrm{e}}\right)$, and resource network $\left(\mathrm{H}_{2 \mathrm{f}}\right)$.

Confirming these hypotheses will indicate that the design and/or use of a MCS can both favor and inhibit organizational resilience. From the hypotheses established it follows that enabling and coercive controls directly influence organizational resilience, which is analyzed here in the cognitive, behavioral, and contextual dimensions, as proposed theoretically by Lengnick-Hall and Beck (2005) and Lengnick-Hall et al. (2011) and operationalized by Akgün and Keskin (2014). 


\section{RESEARCH METHOD AND PROCEDURES}

\subsection{Research Population and Sample}

The population of the research is made up of companies that bought and/or were acquired by others in 2016, according to PwC Brazil's Mergers and Acquisitions in Brazil report, under the argument that the characteristics of these companies cover the basic foundations of organizational resilience. As the December of 2016 report states, of the 597 transactions announced in 2016, the value was disclosed for 182, adding up to a total of US $\$ 37.65$ billion. Companies from the financial and property sector were excluded from the sample, as well as investment funds, foreign companies, and mergers, asset acquisitions, and financial transfers. This resulted in 238 acquiring and/or acquired companies.

The research data were collected using a questionnaire elaborated on the SurveyMonkey platform and sent to divisional managers of these companies via the LinkedIn network in March and April of 2017. The search on LinkedIn was carried out using the terms "manager" and "coordinator", as well as the designation of the companies mapped out in the previous stage. The idea was to consider different roles and organizational areas in the companies studied, given that resilience is made up of different organizational agents. First, the invitation was sent to join the network created on LinkedIn. After acceptance, the link to the research instrument was sent. It was not possible to cover all the 238 companies mapped out, since there were not people registered in the network from all of them, nor was contact possible with managers from 111 firms, most of which were small companies.

The link to the research instrument on SurveyMonkey was sent to the 929 managers who accepted the invitation to take part in the research, in the period from March to April of 2017, and 209 answers were obtained, of which 65 were eliminated because they were incomplete. Therefore, the final research sample covered 144 respondents. Of these, 60 communicated that their company had been bought by another, while 98 stated that the company in which they worked had acquired another or others. Thus, there are both companies that were bought and ones that acquired others in the period analyzed.

\subsection{Research Construct and Measurement of the Variables}

The study has two main constructs: MCS, with enabling and coercive controls (Adler \& Borys, 1996); and organizational resilience, in the cognitive, behavioral, and contextual dimensions (Lengnick-Hall \& Beck, 2005; Lengnick-Hall et al., 2011). These constructs were measured based on multiple items, using the five-point Likert scale, varying from totally disagree to totally agree. Because there were few operationalization measures available in the literature concerning the coercive and enabling controls of the MCS, 16 statements were developed, using definitions and theoretical descriptions, as well as adaptations from previous studies, such as those by Chapman and Kihn (2009), Hartmann and Maas (2011), and Mahama and Cheng (2013).

Given the amplitude of the concept of MCS in the wording of the question of the research instrument, it was clarified that it covers the instruments, mechanisms, and means used to direct and change people's behavior, with the aim of implementing the organization's strategy. It was explained that this definition contemplates all the instruments and systems that managers use to ensure that the behaviors and decisions of individuals are consistent with the objectives and strategies of the organization (Malmi \& Brown, 2008). It was exemplified that, within this scope, the information system itself, the budget, and the performance evaluation system are included, among others.

As an exploratory study is concerned, an exploratory factor analysis was carried out based on common factors, with oblimin rotation and principal axis factoring as the extraction method, to confirm the theoretical groupings (construct validity) of the statements. The exploratory factor analysis grouped the 16 statements into two factors: the first, composed of nine statements and called enabling controls; and the second, with seven statements, called coercive controls, which represented $59.47 \%$ of the total variance explained. The Cronbach's alpha of the enabling and coercive controls constructs was 0.940 and 0.880 , respectively.

With relation to organizational resilience, its active aspect was used, called resilience capacity by LengnickHall and Beck (2005) and Lengnick-Hall et al. (2011). To capture the resilience capacity of the organizations, according to the managers' perception, we used 32 statements extracted from the study by Akgün and Keskin (2014), which empirically tested the propositions of Lengnick-Hall and Beck (2005) and Lengnick-Hall et al. (2011). The exploratory factor analysis was then carried out, which resulted in the elimination of five statements because they contained factor loads below 0.5. Fávero, Belfiore, Silva, and Chan (2009) recommend factor loads starting from 0.5 , when the sample size is within the 120 to 149 respondents range. 
The final analysis resulted in the grouping of six factors, which represent $68.36 \%$ of the total variance explained. These factors were called: (i) conceptual orientation; (ii) constructive direction; (iii) original/improvised agility; (iv) behavioral preparation; (v) psychological security; (vi) extensive resource network. The first two constitute cognitive resilience dimensions, the third and fourth cover behavioral resilience, and the last two involve contextual resilience. These dimensions and variables were also confirmed in the study by Akgün and Keskin (2014). The Cronbach's alphas of these constructs were 0.909 (conceptual orientation), 0.824 (constructive direction), 0.804 (original/improvised agility), 0.881 (behavioral preparation), 0.905 (psychological security), and 0.722 (extensive resource network), which shows the reliability of these measures.

To analyze the data and test the hypotheses, the structured equation modeling (SEM) technique was used, estimated based on partial least squares (PLS). The structural model sought to identify the influence of the coercive and enabling MCSs for each latent variable of resilience, due to resilience relating with various competences and its dimensions working independently and interactively to support the development of different organizational capacities and promote effective responses to environmental change (Lengnick-Hall et al., 2011). This procedure was used by Akgün and Keskin (2014), who investigated whether product innovation capacity mediates the relationship between resilience capacity and performance.

With the aim of minimizing the possible effects of common method bias, Harman's (1976) single factor test was applied to the 45 statements of the constructs. The exploratory factor analysis without rotation produced eight factors that explain $70.1 \%$ of the total variance with eigenvalues $>1.0$. The first factor explained 36.9\% of the total variance. These results indicate that the risks of common method variance are not significance (Podsakoff, MacKenzie, Lee \& Podsakoff, 2003). As procedural measures, we have: (i) preservation of the respondents' anonymity; (ii) guidance that there were no right or wrong answers and that they should answer the questions considering the particular moment; and (iii) a pre-test carried out by two researchers from the area, which led to adjustments in the wording.

\section{DESCRIPTION AND ANALYSIS OF THE DATA}

\subsection{Descriptive Statistics}

Table 1 shows the correlations of the latent variables of the research and the descriptive statistics (mean, standard deviation, and coefficient of variation).

Table 1

Correlation of the latent variables and descriptive statistics

\begin{tabular}{|c|c|c|c|c|c|c|c|c|}
\hline Variables & MCS-E & MCS-C & $\mathrm{CO}$ & CD & IA & BP & PS & RN \\
\hline MCS-E & 1 & & & & & & & \\
\hline MCS-C & $0.738^{*}$ & 1 & & & & & & \\
\hline $\mathrm{CO}$ & $0.501^{*}$ & $0.462^{*}$ & 1 & & & & & \\
\hline $\mathrm{CD}$ & $0.600^{*}$ & $0.453^{*}$ & $0.688^{*}$ & 1 & & & & \\
\hline IA & $0.553^{*}$ & $0.433^{*}$ & $0.582 *$ & $0.622^{*}$ & 1 & & & \\
\hline BP & $0.575^{*}$ & $0.520^{*}$ & $0.703 *$ & $0.611^{*}$ & $0.620^{*}$ & 1 & & \\
\hline PS & -0.087 & 0.040 & $-0.231 *$ & -0.083 & 0.023 & -0.125 & 1 & \\
\hline $\mathrm{RN}$ & $0.406^{*}$ & $0.421^{*}$ & $0.597^{*}$ & $0.459 *$ & $0.458^{*}$ & $0.569 *$ & -0.156 & 1 \\
\hline Mean & 3.43 & 3.44 & 3.36 & 3.56 & 3.18 & 3.44 & 2.30 & 3.55 \\
\hline $\begin{array}{l}\text { Standard } \\
\text { deviation }\end{array}$ & 1.10 & 1.08 & 0.84 & 0.81 & 0.90 & 0.88 & 1.04 & 0.82 \\
\hline $\begin{array}{l}\text { Coefficient } \\
\text { of variation } \\
(\%)\end{array}$ & 32.0 & 31.3 & 25.0 & 22.9 & 28.4 & 25.5 & 45.2 & 23.2 \\
\hline
\end{tabular}

$B P=$ behavioral preparation; $C D=$ constructive direction; $C O=$ conceptual orientation; $I A=$ improvised agility; $M C S-E=$ enabling management control system; MCS-C = coercive management control system; $P S=$ psychological security; $R \mathrm{~N}=$ resource network.

* $=p<0.01$.

Source: Elaborated by the authors. 
The descriptive statistics presented in Table 1 show that, on average, the range of coercive controls (mean of 3.44) does not exceed the enabling controls (mean of 3.43), which indicates that both controls are simultaneously present in the organizations. In this aspect, Jordan and Messner (2012) explained that a change from an enabling MCS to a more coercive control system (or vice-versa) should probably not be considered an exceptional event. Organizations are unlikely to be places of complete harmony and the management control will often be considered coercive (instead of enabling) at least some of the time. The introduction of a new control system can create feelings of coercion among middle managers and employers. However, this does not mean that it has to continue to be seen as coercive (Jordan \& Messner, 2012). This exemplification converges with the event studied in this research, in this case company acquisitions.

Of the six components of organizational resilience, psychological security is the only one that lies below the mean (mean of 2.30) and has a high coefficient of variation, which indicates that the answers of the sample investigated were heterogeneous in this item. Constructive direction receives the highest score (mean of 3.56). The medium scores of resource network and behavioral preparation also stand out (3.55 and 3.48, respectively). Thus, the organizations primarily interpret turbulent situations creatively, then they take advantage of the existing relationships and resources to subsequently devise non-conventional activities.

The Pearson correlation coefficients presented in Table 1 indicate associations between both enabling and coercive MCSs and the components of organizational resilience; the exception being for psychological security, which did not present a statistically significant relationship. The associations of conceptual orientation, constructive direction, improvised agility, and behavioral preparation are greater with the enabling controls compared to the coercive ones, indicating that the enabling controls present a greater relationship with cognitive and behavioral resilience, while resource networks (contextual resilience) present a greater statistically significant association with the coercive controls $(0.421, \mathrm{p}<0.01)$. It is inferred that the specification of activities and steering of actions are related with the network of relationships and mapping of the necessary resources. The enabling and coercive controls also presented positive associations with each other $(0.738, \mathrm{p}<0.01)$, which denotes distinct constructs, as seen in the exploratory factor analysis, but they are independent and complementary (Mundy, 2010).

These results are consistent with the findings of the study by Ahrens and Chapman (2004), in that coercive formalization processes will exist side to side with enabling formalization processes. In the organization investigated, the authors found mechanistic MCSs that aimed to provide standardized and demanding efficiency levels, but the enabling logic was found in the managers' role, which was not just to follow head office rules, but employ the company's guidelines with the aim of achieving customer satisfaction. The studies conducted by Free (2007), Jørgensen and Messner (2009), and Jordan and Messner (2012) also indicate that enabling and coercive controls are not mutually exclusive.

Thus, prescribed procedures and the specific outlining of functions (coercive controls), for example, may contribute to better task performance and economy of time. This economy can favor the search for opportunities, experimentation, and learning (enabling controls).

\subsection{Testing the Hypotheses}

As recommended by Hair, Hult, Ringle, and Sarstedt (2016), the measurement model and structural model were analyzed separately.

\subsubsection{Measurement model}

Measurement model adequacy implies evaluating the reliability (individual and composite reliability) and validity (convergent and discriminant validity) of the constructs' measures (Hair et al., 2016), whose results feature in Table 2.

\section{Table 2}

Results of the measurement model

\begin{tabular}{|c|c|c|c|c|c|c|c|c|c|c|c|}
\hline \multirow[t]{2}{*}{ Variables } & \multirow[t]{2}{*}{$\begin{array}{c}\text { Composite } \\
\text { reliability }>0.70\end{array}$} & \multirow[t]{2}{*}{$\begin{array}{c}\text { Cronbach's } \\
\text { Alpha }>\mathbf{0 . 7 0}\end{array}$} & \multirow[t]{2}{*}{$\begin{array}{c}\text { AVE > } \\
0.50\end{array}$} & \multicolumn{8}{|c|}{ Discriminant validity } \\
\hline & & & & IA & $\mathrm{CO}$ & BP & RN & MCS-C & MCS-E & PS & CD \\
\hline IA & 0.880 & 0.829 & 0.596 & 0.772 & & & & & & & \\
\hline $\mathrm{CO}$ & 0.932 & 0.909 & 0.732 & 0.582 & 0.855 & & & & & & \\
\hline $\mathrm{BP}$ & 0.909 & 0.880 & 0.625 & 0.620 & 0.703 & 0.790 & & & & & \\
\hline RN & 0.840 & 0.718 & 0.641 & 0.458 & 0.597 & 0.569 & 0.801 & & & & \\
\hline MCS-C & 0.908 & 0.882 & 0.587 & 0.433 & 0.462 & 0.520 & 0.421 & 0.766 & & & \\
\hline
\end{tabular}


Table 2

Cont.

\begin{tabular}{lcccccccccccc}
\hline Variables & $\begin{array}{c}\text { Composite } \\
\text { reliability } \mathbf{8 . 7 0}\end{array}$ & $\begin{array}{c}\text { Cronbach's } \\
\text { Alpha }>\mathbf{0 . 7 0}\end{array}$ & $\begin{array}{c}\text { AVE }> \\
\mathbf{0 . 5 0}\end{array}$ & \multicolumn{5}{c}{ Discriminant validity } \\
\hline MCS-E & 0.949 & 0.940 & 0.676 & 0.553 & 0.501 & 0.575 & 0.406 & 0.738 & $\mathbf{0 . 8 2 2}$ & \\
\hline PS & 0.913 & 0.905 & 0.727 & 0.023 & -0.231 & -0.125 & -0.156 & 0.040 & -0.087 & $\mathbf{0 . 8 5 3}$ \\
\hline CD & 0.884 & 0.827 & 0.657 & 0.622 & 0.688 & 0.611 & 0.459 & 0.453 & 0.600 & -0.083 & $\mathbf{0 . 8 1 1}$ \\
\hline
\end{tabular}

Note: Values in bold mean the squared roots of the average variance extracted (AVE), with the values of this diagonal being greater than the correlation coefficients of the other constructs.

$A V E=$ average variance extracted; $B P=$ behavioral preparation; $C O=$ conceptual orientation; $I A=$ improvised agility; $C D=$ constructive direction; MCS-E = enabling management control system; MCS-C = coercive management control system; PS = psychological security; $R N=$ resource network.

Source: Elaborated by the authors.

The results presented in Table 2 indicate that the model is adequate, since the Cronbach's alpha, which assesses the reliability of the scale, and the composite reliability presented values greater than the acceptable minimum of 0.70 , which validates the internal consistency of the model (Hair et al., 2016).

The convergent validity was evaluated by the average variance extracted (AVE) of each latent variable, in which all the constructs show values above 0.50 , which indicates adequate convergent validity (Hair et al., 2016). Finally, the discriminant validity was evaluated, by comparing the squared roots of the AVE of each latent variable with the correlations between them. All the AVE squared roots were greater than the correlation coefficients, suggesting acceptable discriminant validity, as prescribed by Fornell and Larcker (1981). The discriminant validity was also evaluated using the Chin (1998) criterion, in which the values of the factor loads were greater in the latent variables than in others, validating the inclusion of all the latent variables in the analysis.

\subsubsection{Structural model}

To test the structural model, which includes the hypotheses and the exploratory paths, the bootstrapping procedure was carried out with a sample of 144 cases and 1,000 resamplings and the path coefficients and their significance were analyzed. Then an evaluation of the structural model was also carried out based on (i) the Pearson coefficient of determination $\left(\mathrm{R}^{2}\right)$, which supports the predictive validity of the model, (ii) the predictive relevance $\left(\mathrm{Q}^{2}\right)$ or Stone-Geisser indicator, in which the values of the endogenous variables should be greater than 0 , and (iii) the size of effect $\left(\mathrm{F}^{2}\right)$ or Cohen indicator (Hair et al., 2016). Table 3 presents the path coefficients, the associated $t$ values and their significance, and the $\mathrm{R}^{2}$, $\mathrm{Q}^{2}$, and $\mathrm{F}^{2}$ statistics of the endogenous constructs.

Table 3

Path coefficients and evaluation of the structural model $(n=144)$

Path to

\begin{tabular}{|c|c|c|c|c|c|c|}
\hline \multirow[b]{3}{*}{ Path from } & \multicolumn{6}{|c|}{ Path to } \\
\hline & \multicolumn{2}{|c|}{ Cognitive resilience } & \multicolumn{2}{|c|}{ Behavioral resilience } & \multicolumn{2}{|c|}{ Contextual resilience } \\
\hline & $\mathrm{CO}$ & CD & IA & BP & PS & RN \\
\hline \multirow{2}{*}{ Enabling control } & $0.353^{* *}$ & $0.582^{* * *}$ & $0.514^{* * *}$ & $0.420^{* * *}$ & $-0.255^{*}$ & $0.208^{*}$ \\
\hline & $(3.297)$ & $(5.717)$ & $(5.792)$ & $(4.033)$ & $(1.972)$ & $(2.016)$ \\
\hline \multirow{2}{*}{ Coercive control } & 0.201 & 0.024 & 0.054 & 0.210 & $0.228^{*}$ & $0.268^{*}$ \\
\hline & $(1.717)$ & $(0.342)$ & $(0.773)$ & $(1.783)$ & $(2.102)$ & $(2.104)$ \\
\hline $\mathrm{R}^{2}$ & 0.270 & 0.360 & 0.307 & 0.351 & 0.031 & 0.197 \\
\hline $\begin{array}{l}\text { Predictive } \\
\text { relevance }\left(Q^{2}\right)\end{array}$ & 0.179 & 0.217 & 0.170 & 0.206 & -0.006 & 0.111 \\
\hline Size of effect $\left(\mathrm{F}^{2}\right)$ & 0.589 & 0.425 & 0.390 & 0.465 & 0.530 & 0.297 \\
\hline
\end{tabular}

Note: $t$ value in parentheses.

$B P=$ behavioral preparation; $C O=$ conceptual orientation; $I A=$ improvised agility; $C D=$ constructive direction; $P S=$ psychological security; $R N=$ network of resources.

*** $=p<0.001 ;{ }^{* *}=p<0.01 ;{ }^{*}=p<0.05$.

Source: Elaborated by the authors. 
Confirming expectations, the results presented in Table 3 suggest various associations between enabling MCSs and organizational resilience in the cognitive, behavioral, and contextual modalities. Positive and significant relationships are found between enabling controls and conceptual orientation $(0.353, \mathrm{p}<0.01)$, constructive direction $(0.582, \mathrm{p}<0.001)$, improvised agility $(0.514, \mathrm{p}<$ $0.001)$, behavioral preparation $(0.420, \mathrm{p}<0.001)$, and resource network $(0.208, \mathrm{p}<0.05)$. In addition, the results suggest a negative association between enabling controls and psychological security $(-0.255, \mathrm{p}<0.05)$, but the explanatory power of this variable is practically null $\left(\mathrm{R}^{2}\right.$ of 0.031$)$ and presents a predictive relevance $\left(\mathrm{Q}^{2}\right)$ value close to $0(-0.006)$. Therefore, the enabling controls positively influence cognitive, behavioral, and contextual resilience through the resource network. These results provide support for the non-rejection of $\mathrm{H}_{1}$, which states that the enabling controls of an MCS have a positive association with organizational resilience, except for $\mathrm{H}_{1 \mathrm{f}}$, which foresaw a positive association between enabling MCSs and psychological security and was rejected.

Contrary to expectations, the results of Table 3 do not show any negative and significant associations between coercive controls and organizational resilience. The relationships between the coercive MCSs and both cognitive and behavioral resilience even presented positive but non-significant coefficients. In addition, a positive and significant relationship with contextual resilience is observed, through psychological security $(0.228, \mathrm{p}<$ $0.05)$ and resource network $(0.268, \mathrm{p}<0.05)$. These results provide support for the rejection of $\mathrm{H}_{2}$, which states that the coercive controls of an MCS have a negative association with organizational resilience. They also reinforce the importance of the simultaneous presence of enabling and coercive controls, which calls for future studies.

\subsection{Discussion of the Results}

The assumption of this study was that MCSs can play a coercive and enabling role in organizations and that this is reflected in organizational resilience, analyzed here from the active perspective, in the cognitive, behavioral, and contextual dimensions, as proposed by Lengnick-Hall and Beck (2005) and Lengnick-Hall et al. (2011). The results show that enabling controls positively influence all the types of resilience investigated, especially improvised agility, constructive direction, and behavioral preparation. The exception occurred with psychological security, which presented a negative coefficient.

These results indicate that MCSs designed with characteristics that favor communication, intergroup participation, task mastery, and flexible and decentralized relationships, classified by Adler and Borrys (1996) as enabling, contribute to organizations dealing effectively with turbulences and adversities. The MCS design, in this modality, develops capacities to create opportunities when faced with disruptive events. According to Free (2007), the enabling use of management controls seeks to capitalize on managers' intelligence, giving them the freedom to innovate amidst contingencies, unexpected events, and obstacles that may impede the organization's objectives and productivity.

In the event of discontinuities and turbulences, people are more likely to follow unconventional strategic repertoires, as well as having a complex and varied list of actions that may be used when faced with an unplanned event (Lengnick-Hall \& Beck, 2005). These results indicate that MCSs planned to identify opportunities for improvement that favor experimentation instead of rigid processes and excessive control enable managers to perceive experiences positively and develop actions before they are needed, in order to ensure that the organization benefits before the situation arises. Therefore, enabling controls contribute to organizations prospering in the event of adversity, given that they influence organizational resilience capacity.

Nilsson (2002) analyzed the implications for the design and use of the MCSs in four Swedish firms after being acquired by another. The results showed that in some cases there was a potential mismatch in the design and use of the MCS of the acquired company. In these cases, measures were taken to ensure that the informational needs, both of the acquirer and of the firms acquired, were met as much as possible. The results suggest that executives should not follow a uniform standardized procedure for integrating acquired firms, but should instead adopt a flexible approach that meets the informational needs of both companies, acquirer and acquired. Enabling controls favor organizational memory, which captures the lessons learned from experience (Wouters \& Wilderom, 2008), and are planned to increase the capacities of users and leverage their abilities and intelligence (Ahrens \& Chapman, 2004).

The association between enabling controls and the dimensions of improvised agility, constructive direction, and behavioral preparation occurs because, in this type of MCS, experimentation and the search for and sharing of information are incentivized, besides allowing people to adopt a different course of action from planned, when necessary. According to Adler and Borys (1996), under the enabling logic there is a strong formal and informal incentive that encourages workers to identify 
and propose improvements in the work methods. In an enabling system, mistakes or inefficiencies become opportunities for employees to take corrective measures and make improvements in the processes (Burney et al., 2017). In this aspect, it is assumed that this type of system allows organizations to have various alternatives for dealing with different scenarios, which makes them more resilient.

The negative association between enabling controls and psychological security may be the result of psychological security statements related to interpersonal risks, for example the risk of people being seen as ignorant for asking questions or seeking information, or even being seen as incompetent for asking for help, admitting mistakes, or experimenting. Given that enabling controls promote flexibility (Chapman \& Kihn, 2009) and experimentation (Wouters \& Wilderom, 2008), it is assumed that the greater the presence of the enabling characteristic, the smaller the risk of people being seen as incompetent or ignorant for admitting mistakes and seeking information. Free (2007) suggests that the following are inherent to enabling controls: interactive dialogue; promoting trust; learning from mistakes; and facilitating problem solving. The positive association with coercive controls is explained as being because they are based on centralization, predefined routines, and the specification of rules and detailed expectations (Ahrens \& Chapman, 2004; Free, 2007), in which any deviation is seen as suspicious (Adler \& Borrys, 1996).

The results also indicate for the presence of coercive and enabling controls that these are interdependent and complementary (Mundy, 2010) and that coercive controls do not have a positive association with the dimensions of organizational resilience, and even positively influence contextual resilience. Thus, internal and external relationships and the mapping of resources needed to carry out activities are previously established, since coercive controls establish a specific division of tasks (Adler \& Borrys, 1996) and steer people's actions towards complying with the standards specified by senior management (Adler \& Borrys, 1996; Ahrens \& Chapman,
2004). The intention of this type of system is to monitor people regarding compliance with company procedures (Mahama \& Cheng, 2013); thus, relationship networks are already previously established and the necessary resources allocated. Therefore, MCSs are used to achieve organizational objectives and to enable employees to seek opportunities and resolve problems (Mundy, 2010; Tessier \& Otley, 2012).

Due to these results, the theoretical-empirical evidence (Ahrens \& Chapman, 2004; Free, 2007; Hartmann \& Maas, 2011; Mundy, 2010), and the positive correlations between both types of control and the resilience dimensions presented in Table 1, it is speculated that the dual role of control (Tessier \& Otley, 2012) may be reflected in organizational resilience. It is believed that organizational resilience capacity is enhanced when a coercive control becomes more enabling, or vice-versa, or, also, the combined use of coercive controls with enabling ones creates dynamic tensions (Mundy, 2010; Tessier \& Otley, 2012) and is possibly reflected in the resilience of organizations, which requires future research. Ahrens and Chapman (2004) already suggested that purely organic or mechanistic forms of organization are rarely found in practice.

The results of the research also reinforce the assumption that resilience is a development process instead of a static result (Akgün \& Keskin, 2014). Therefore, it constitutes organizational capacity, as has already been reinforced by one line of literature (Akgün \& Keskin, 2014; Lengnick-Hall \& Beck, 2005; Linnenluecke, 2017). Linnenluecke (2017) argues that resilience implies an organization's capacity to learn, adopt, self-organize, and act in advance of events. According to Akgün and Keskin (2014), resilience capacity also expands people's knowledge, abilities, and technical capacities, was well as behavioral repertoires that can provide them with options for improvising and pursuing different alternatives in turbulent environmental conditions. Given the results obtained in this study, it is necessary for the design and, consequently, the respective use of the MCS to be aligned for this purpose.

\section{CONCLUSIONS}

This study examined the impacts of enabling and coercive MCSs on organizational resilience. The results showed the presence of both types of control in the organizations studied, and the evidence is consistent with the literature's approach regarding the dual role of the control, in that the MCSs adopted in these organizations seek to manage dynamic tensions by balancing efficiency versus experimentation, freedom versus restriction, and empowerment versus liability. Enabling controls are positively associated with the three types of resilience 
investigated (cognitive, behavioral, and contextual). Thus, they favor interpreting uncertain situations creatively, they help in devising unconventional activities, and they optimize relationships and resources. As for coercive controls, these only presented positive relationships with contextual resilience in regards to psychological security and resource networks.

\subsection{Theoretical Implications}

This study presents theoretical implications, especially for the emerging body of literature on enabling and coercive MCSs. The first studies from the line of research were conducted using case studies and their core concern was to transpose the framework from Adler and Borys (1996) to the area of MCSs and specifically understand: (i) how managers pursue efficiency and flexibility objectives using enabling MCSs (Ahrens \& Chapman, 2004); and (ii) whether the concepts of coercive and enabling use in the accounting area are also useful in understanding interorganizational relationships (Free, 2007); as well as (iii) identifying characteristics of the development process of a more enabling MCS (Wouters \& Wilderom, 2008). Then, the area's concern was to understand the impacts of enabling MCSs on organizational (Chapman \& Kihn, 2009) and individual results (Mahama \& Cheng, 2013; Souza \& Beuren, 2018). This study expands the literature by focusing on MCSs as antecedents of resilience capacity.

The previous literature has mainly used the enabling approach and adopts the assumption that the use of coercive controls is generally perceived in a negative way (Radtke \& Widener, 2016). However, studies (Ahrens \& Chapman, 2004; Jordan \& Messner, 2012) have revealed that these types of controls are not exclusive, but instead complementary, coexisting side by side in organizations in the search for efficiency and flexibility. The results indicate that both are present in the organizations studied and that coercive controls do not have a negative influence on resilience, even presenting a positive association with the contextual dimension, and thus prompting future studies. The research instrument concerning enabling and coercive controls was also expanded and empirically tested, which was a gap observed in the literature. In addition, it meets the recommendations of previous studies (Annarelli \& Nonino, 2016; Chewning et al., 2012; Ignatiadis \& Nandhakumar, 2007) by contemplating a larger system, the MCS, instead of specific systems, such as the ERP, with the aim of reinforcing the idea that the design and use of the system influence organizational resilience. It also answers the call from studies (Ruiz-Martin et al., 2018) regarding the approach of antecedents of organizational resilience, by considering mechanisms (MCSs) that go beyond human resources strategy.

\subsection{Practical Implications}

This study also presents practical implications, since it reveals that enabling characteristics of an MCS have a significant influence over the resilience dimensions analyzed, while coercive controls positively influence contextual resilience. By doing so, it is emphasized that the design and use of an MCS can contribute to the organization's capacity for dealing with turbulences and unexpected events in advance. The MCS provides support for managing and controlling interruptions and unexpected events in order to shorten unfavorable events and maximize the organization's speed of recovery to its original state or a new more desirable one (Annarelli \& Nonino, 2016).

Although both control systems, enabling and coercive, presented significant correlations with the resilience dimensions, in the theoretical model proposed, the enabling control exceeded the coercive control in its association with organizational resilience. The results of the study suggest that enabling controls are important elements of an MCS, and they influence subsequent results and behaviors and, in the case of this research, organizational resilience capacity. Thus, organizations need to pay attention to planning MCSs and how they use them, since these are associated with individuals' attitudes and behaviors, which are reflected in organizational results.

\subsection{Limitations and Future Research}

Interpreting the results requires prudence, since they are based on the respondents' perceptions. Subjective aspects may have been present at the time their answers were given, leading them towards a desirable situation in the organization. The research instrument used was based on measures that have been recently developed in the literature and, although the measurement model indicated that these are valid and reliable, reapplication of them is recommended. Although a definition and exemplifications of MCS were provided in the research instrument, the respondents may have interpreted its concept differently and concentrated on a particular instrument, such as the information system or budget, among others.

The effects observed in the analyses do not indicate causal relationships, but instead statistical associations that are consistent with the theory (Chapman \& Kihn, 
2009). Therefore, the causality relationships should be interpreted with caution, since the results show statistical associations between the paths of the model. Alternative research methods, such as longitudinal case studies, may provide more appropriate information regarding the causal relationships of the model. Case studies could be carried out to understand how MCSs contribute to the resilience process when some rupture/unexpected event occurs in an organization (such as an economic recession, environmental catastrophe, etc.). In addition, the results are limited to the sample investigated, which does not enable generalization to different contexts.
Nonetheless, the model proposed in this study serves as inspiration for future studies. Other dimensions of resilience could be examined, such as the planned and adapted resilience proposed by Lee et al. (2013) or the operational and strategic resilience from Välikangas and Romme (2012). Also, other taxonomies of MCS could be used to understand how the design and use of an MCS affect organizational resilience capacity. Future research could also consider aspects of individual resilience and verify to what extent enabling and coercive controls contribute to the resilience capacity of individuals when faced with adverse conditions.

\section{REFERENCES}

Adler, P. S., \& Borys, B. (1996). Two types of bureaucracy: Enabling and coercive. Administrative Science Quarterly, 41(1), 61-89.

Ahrens, T., \& Chapman, C. S. (2004). Accounting for flexibility and efficiency: A field study of management control systems in a restaurant chain. Contemporary Accounting Research, 21(2), 271-301.

Akgün, A. E., \& Keskin, H. (2014). Organisational resilience capacity and firm product innovativeness and performance. International Journal of Production Research, 52(23), 6918-6937.

Alvarenga, M. Z., Santos, W. R., \& Pelissari, A. S. (2017). O relacionamento colaborativo e os sistemas e tecnologias de informação impactam a resiliência das cadeias de suprimentos? Espacios (Caracas), 38(1), 3-21.

Annarelli, A., \& Nonino, F. (2016). Strategic and operational management of organizational resilience: Current state of research and future directions. Omega, 62(1), 1-18.

Barasa, E., Mbau, R., \& Gilson, L. (2018). What is resilience and how can it be nurtured? A systematic review of empirical literature on organizational resilience. International Journal of Health Policy and Management, 7(6), 491-503.

Bhamra, R., Dani, S., \& Burnard, K. (2011). Resilience: The concept, a literature review and future directions. International Journal of Production Research, 49(18), 53755393.

Bisbe, J., \& Otley, D. (2004). The effects of the interactive use of management control systems on product innovation. Accounting, Organizations and Society, 29(8), 709-737.

Burney, L. L., Radtke, R. R., \& Widener, S. K. (2017). The intersection of "bad apples" "bad barrels," and the enabling use of performance measurement systems. Journal of Information Systems, 31(2), 25-48.

Chapman, C. S., \& Kihn, L. A. (2009). Information system integration, enabling control and performance. Accounting, Organizations and Society, 34(2), 151-169.

Chenhall, R. H. (2003). Management control systems design within its organizational context: Findings from contingencybased research and directions for the future. Accounting, Organizations and Society, 28(2), 127-168.
Chewning, L. V., Lai, C. H., \& Doerfel, M. L. (2012). Organizational resilience and using information and communication technologies to rebuild communication structures. Management Communication Quarterly, 27(2), 237-263.

Chin, W. W. (1998). The partial least squares approach for structural equation modeling. In Marcoulides, G. A. (Ed.), Modern methods for business research (pp. 295-336). Mahwah, NJ: Lawrence Erlbaum Associates.

Fávero, L. P., Belfior, E. P., Silva, F. L. \& Chan, B. L. (2009). Análise de dados: Modelagem multivariada para tomada de decisões. Rio de Janeiro, RJ: Elsevier.

Fornell, C., \& Larcker, D. F. (1981). Structural equation models with unobservable variables and measurement error: Algebra and statistics. Journal of Marketing Research, 18(3), 382-388.

Free, C. (2007). Supply-chain accounting practices in the UK retail sector: Enabling or coercing collaboration? Contemporary Accounting Research, 24(3), 897-933.

Gittell, J. H., Cameron, K., Lim, S., \& Rivas, V. (2006). Relationships, layoffs, and organizational resilience airline industry responses to September 11. The Journal of Applied Behavioral Science, 42(3), 300-329.

Hair, J. F., Jr., Hult, G. T. M., Ringle, C., \& Sarstedt, M. (2016). A primer on partial least squares structural equation modeling (PLS-SEM). Thousand Oaks, CA: Sage Publications.

Harman, H. H. (1976). Modern factor analysis. Chicago, IL: University of Chicago press.

Hartmann, F. G., \& Maas, V. S. (2011). The effects of uncertainty on the roles of controllers and budgets: An exploratory study. Accounting and Business Research, 41(5), 439-458.

Henttu-Aho, T. (2016). Enabling characteristics of new budgeting practice and the role of controller. Qualitative Research in Accounting \& Management, 13(1), 31-56.

Holling, C. S. (1973). Resilience and stability of ecological systems. Annual Review of Ecology and Systematics, 4(1), $1-23$.

Hosseini, S., Barker, K., \& Ramirez-Marquez, J. E. (2016). A review of definitions and measures of system resilience. Reliability Engineering \& System Safety, 145(1), 47-61. 
Hoy, W. K., \& Sweetland, S. R. (2001). Designing better schools: The meaning and measure of enabling school structures. Educational Administration Quarterly, 37(3), 296-321.

Ignatiadis, I., \& Nandhakumar, J. (2007). The impact of enterprise systems on organizational resilience. Journal of Information Technology, 22(1), 36-43.

Jordan, S., \& Messner, M. (2012). Enabling control and the problem of incomplete performance indicators. Accounting, Organizations and Society, 37(8), 544-564.

Jørgensen, B., \& Messner, M. (2009). Management control in new product development: The dynamics of managing flexibility and efficiency. Journal of Management Accounting Research, 21(1), 99-124.

Lee, A. V., Vargo, J., \& Seville, E. (2013). Developing a tool to measure and compare organizations' resilience. Natural Hazards Review, 14(1), 29-41.

Lengnick-Hall, C. A., \& Beck, T. E. (2005). Adaptive fit versus robust transformation: How organizations respond to environmental change. Journal of Management, 31(5), 738-757.

Lengnick-Hall, C. A., Beck, T. E., \& Lengnick-Hall, M. L. (2011). Developing a capacity for organizational resilience through strategic human resource management. Human Resource Management Review, 21(3), 243-255.

Linnenluecke, M. K. (2017). Resilience in business and management research: A review of influential publications and a research agenda. International Journal of Management Reviews, 19(1), 4-30.

Luthans, F., Vogelgesang, G. R., \& Lester, P. B. (2006). Developing the psychological capital of resiliency. Human Resource Development Review, 5(1), 25-44.

Mahama, H., \& Cheng, M. M. (2013). The effect of managers' enabling perceptions on costing system use, psychological empowerment, and task performance. Behavioral Research in Accounting, 25(1), 89-114.

Malmi, T., \& Brown, D. A. (2008). Management control systems as a package: Opportunities, challenges and research directions. Management Accounting Research, 19(4), 287-300.

Meyer, A. D. (1982). Adapting to environmental jolts. Administrative Science Quarterly, 27(1), 515-537.

Mundy, J. (2010). Creating dynamic tensions through a balanced use of management control systems. Accounting, Organizations and Society, 35(5), 499-523.
Nilsson, F. (2002). Strategy and management control systems: A study of the design and use of management control systems following takeover. Accounting \& Finance, 42(1), 41-71.

Podsakoff, P. M., MacKenzie, S. B., Lee, J. Y., \& Podsakoff, N. P. (2003). Common method biases in behavioral research: A critical review of the literature and recommended remedies. Journal of Applied Psychology, 88(5), 879-903.

Radtke, R. R., \& Widener, S. K. (2016). The complex world of control: Integration of ethics and uses of control. In Performance Measurement and Management Control: Contemporary Issues (pp. 17-38). Somerville, MA: Emerald Group Publishing.

Ruiz-Martin, C., López-Paredes, A., \& Wainer, G. (2018). What we know and do not know about organizational resilience. International Journal of Production Management and Engineering, 6(1), 11-28.

Sánchez, J. M., Vélez, M. L., \& Ramón-Jerónimo, M. A. (2012). Do suppliers' formal controls damage distributors' trust? Journal of Business Research, 65(7), 896-906.

Sheffi, Y., \& Rice, J. B. Jr. (2005). A supply chain view of the resilient enterprise. MIT Sloan Management Review, 47(1), 41-48.

Somers, S. (2009). Measuring resilience potential: An adaptive strategy for organizational crisis planning. Journal of Contingencies and Crisis Management, 17(1), 12-23.

Souza, G. E., \& Beuren, I. M. (2018). Reflexos do sistema de mensuração de desempenho habilitante na performance de tarefas e satisfação no trabalho. Revista Contabilidade \& Finanças, 29(77), 194-212.

Staw, B. M., Sandelands, L. E., \& Dutton, J. E. (1981). Threat rigidity effects in organizational behavior: A multilevel analysis. Administrative Science Quarterly, 26(4), 501-524.

Tessier, S., \& Otley, D. (2012). A conceptual development of Simons' Levers of Control framework. Management Accounting Research, 23(3), 171-185.

Välikangas, L., \& Romme, G. (2012). Building resilience capabilities at "Big Brown Box, Inc." Strategy \& Leadership, 40(4), 43-45.

Wouters, M., \& Wilderom, C. (2008). Developing performancemeasurement systems as enabling formalization: A longitudinal field study of a logistics department. Accounting, Organizations and Society, 33(4), 488-516. 


\section{APPENDIX}

\section{Questionnaire}

\section{Coercive management control systems}

I perceive that the MCSs are planned in order to steer the actions of people in the company towards complying with the standards specified by senior management.

I perceive that the MCSs are planned to specify the activities that people should carry out within the company. I perceive that the MCSs are planned to establish a specific division of tasks for each company employee.

I perceive that the MCSs are planned with the aim of reporting to superiors whether the actions of people in the company conform to what was planned.

I perceive that the MCSs are planned with the aim of monitoring people with regards to compliance with the company's procedures*.

I perceive that the MCSs are used to communicate to people in the company how they should behave**.

I perceive that the MCSs are used as an instrument to delimit the authority of managers' decisions ${ }^{* *}$.

\section{Enabling management control systems}

I analyze the MCS information by focusing on alternatives for improving the operations under my control ${ }^{* * *}$.

I perceive that the MCSs are implemented with charateristics that favor flexible and decentralized relationships, which incentivize task mastery, intergroup participation, explicit communication, and trust.

I perceive that the MCSs are planned to capitalize on the managers' intelligence, giving them the freedom to innovate amidst contingencies, unexpected events, and obstacles that may impede the organization's objectives and productivity. I perceive that the MCSs are planned to increase people's knowledge regarding how their sector works as a whole ${ }^{\star * *}$. I perceive that the MCSs are planned with the aim of identifying opportunities for improvement, revising methods, and carrying out the work more efficiently. I perceive that the MCSs are planned with the aim of enabling people in the company to work more efficiently*. I perceive that the MCSs provide a structure for discussing the decisions and actions of managers in the company ${ }^{* *}$. I perceive that the MCSs are used by people in the company to discuss the effects of organizational and environmental changes ${ }^{* *}$.

I perceive that the MCSs are used in order to help people deal directly with the inevitable contingencies of their work.

Source: ${ }^{*}$ Mahama and Cheng (2013); ${ }^{* *}$ Hartmann and Maas (2011); ${ }^{* \star}$ Chapman and Kihn (2009). The other statements were elaborated based on the propositions of Adler and Borys (1996), Ahrens and Chapman (2004), and Free (2007).

\section{Organizational Resilience}

\section{Dimension: conceptual orientation}

We have a strong sense of purpose, fundamental values, and a genuine vision.

We have strong core values, together with a sense of purpose and identity, which encourage us to use the conditions so that they enable problem solving and action instead of paths that lead to any threat rigidity or dysfunctional escalation of commitment.

We have a predominant vocabulary that implies capacity, influence, competence, consistent fundamental values, and a clear sense of direction.

We have a highly visible moral purpose that enbales us to motivate employees, perceive opportunities, and free up physical and psychological resources.

We have an attitude that balances the contradictory forces of confidence and experience against skepticism, caution, and a search for new information.

\section{Dimension: constructive direction}

We have a mentality that requires a solid understanding of reality and an implacable desire to question fundamental assumptions.

We incentivize creativity and seek opportunities to develop new competences, instead of emphasizing standardization and the need for control.

We have a mentality that enables interpretation of the world and a positive perception of experiences.

We concentrate on interpretations and judgements of specific situations, instead of programmed explanations.

\section{Dimension: improvised agility}

We have the capacity, in the event of turbulences, to follow a considerably different course of action from what is considered to be the norm.

People engage in unconventional strategic repertoires (those that break from the industry norms) instead of simple strategic repertoires (those that tend to be concerned with a single type of action) in order to take counter-intuitive actions.

We have a complex and varied list of actions that enables us to follow a course of action that is different from the norm in our organization. 
In our organization, we have a diversified number of competitive actions available to quickly adopt unexpected responses in the event of market changes.

We engage in developing useful habits and practices, especially repetitive ones, which are learned routines that provide the first response to any unexpected threat.

\section{Dimension: behavioral preparation}

We develop values that lead to investigative habits instead of assumptions.

We develop values that lead to collaborative routines instead of rivalries.

We carry out actions and investments before they are necessary to guarantee that we are able to benefit in situtions that arise.

We deliberately unlearn obsolete information or dysfunctional heuristics.

We quickly eliminate behaviors that constrain us with the aim of developing new competences.

In our organization, we have the capacity to detect an opportunity that other companies without our competences could lose.

\section{Dimension: psychological security}

In our organization, people perceive that their work environment steers them towards running interpersonal risks, the risk of being seen as ignorant for asking questions or seeking information.

In our organization, people perceive that their work environment steers them towards running interpersonal risks, the risk of being seen as incompetent for asking for help, admitting mistakes, or experimenting.

In our organization, people perceive that their work environment steers them towards running interpersonal risks, the risk of being seen as negative when they provide critical feedback.

In our organization, people perceive that their work environment steers them towards running interpersonal risks, the inability to seek feedback for fear of taking up someone's time or taking advantage of their goodwill.

\section{Dimension: resource network}

In our organization, people establish relationships with others who can share key resources.

We use relationships with supplier contacts and strategic alliances in order to guarantee the resources needed to support adaptation iniciatives.

In our organization, we ensure that the bonds with the various environmental agents are maintained, thus reinforcing social capital beyond the boundaries of the company.

Source: Akgün and Keskin (2014). 